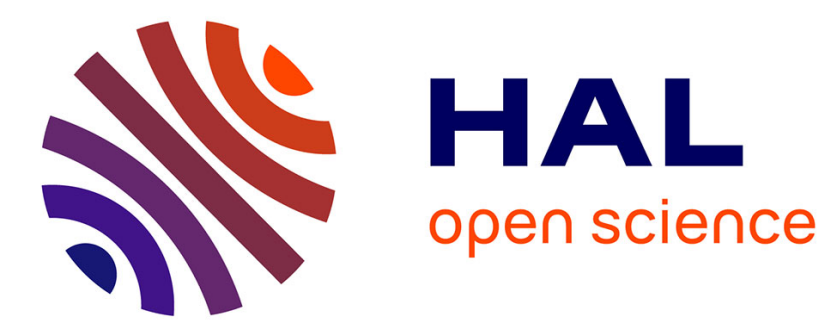

\title{
Parental violence and adolescent mental health
}

Kirsi Peltonen, Noora Ellonen, Helmer B. Larsen, Karin Helweg-Larsen

\section{To cite this version:}

Kirsi Peltonen, Noora Ellonen, Helmer B. Larsen, Karin Helweg-Larsen. Parental violence and adolescent mental health. European Child and Adolescent Psychiatry, 2010, pp.813-822. 10.1007/s00787010-0130-8 . hal-00619926

\section{HAL Id: hal-00619926 \\ https://hal.science/hal-00619926}

Submitted on 7 Sep 2011

HAL is a multi-disciplinary open access archive for the deposit and dissemination of scientific research documents, whether they are published or not. The documents may come from teaching and research institutions in France or abroad, or from public or private research centers.
L'archive ouverte pluridisciplinaire HAL, est destinée au dépôt et à la diffusion de documents scientifiques de niveau recherche, publiés ou non, émanant des établissements d'enseignement et de recherche français ou étrangers, des laboratoires publics ou privés. 
Parental violence and adolescent mental health

Kirsi Peltonen ${ }^{1}$, Noora Ellonen ${ }^{2}$, Helmer B. Larsen ${ }^{3}$, Karin Helweg-Larsen ${ }^{4}$

${ }^{1}$ University of Tampere, Department of Psychology, 33014, University of Tampere, Finland

${ }^{2}$ Police College of Finland, Box 123, 33721 Tampere, Finland

${ }^{3}$ Department of Psychology, University of Copenhagen, Øster Farimagsgade 2A, 1353Copenhagen K, Denmark

${ }^{4}$ National Institute of Public Health, University of Southern Denmark, Øster Farimagsgade 5A, 1399 Copenhagen K, Denmark

Corresponding author: Kirsi Peltonen,

phone: +358(0)335516577; fax: 358(0)33551; email: kirsi.peltonen@uta.fi 


\begin{abstract}
Being the target of parental violent acts decreases child adjustment and increases the likelihood of mental health problems in childhood and adolescence. Our study analyzes how different types of parental violence ranging from verbal threats and swearing to hitting and kicking a child, are associated with child adjustment, indicated by SDQ total problem score, internalizing and externalizing problems as well as prosocial behaviour. We also study whether girls and boys and youths in two Nordic countries respond differently to parental violence. The data consists of a large-scale community sample of $15-16$ year old Finnish $(n=5,762)$ and Danish $(n=3,943)$ adolescents. The representative data of continental Finland and its Finnish and Swedish speaking 9th graders as well as representative data of Danish $9^{\text {th }}$ grade pupils was collected by the Police College of Finland and in Denmark by the National Institute of Public Health, University of Southern Denmark. The results show a clear dose-response effect between parental violent behaviour and the adolescent's problems. The more severe forms of parental violence were associated with higher levels of SDQ total difficulties and internalizing and externalizing symptoms. There was also a connection between parental violence and the deterioration of prosocial behaviour. The association was gender and nationality specific. The findings imply a high prevalence of parental violence and adverse mental health among the affected Finnish and Danish adolescents. Though the laws have been set in motion to prevent the use of parental physical violence the challenges remain in several domains of child protection, general health care, prevention and intervention.
\end{abstract}

Key words: parental violence, adolescence, mental health 


\section{Parental violence and mental health}

According to the Child Maltreatment Classification Scheme MCS [1], six maltreatment subtypes can be distinguished: physical abuse, sexual abuse, failure to provide (a form of physical neglect), lack of supervision (another form of physical neglect), emotional maltreatment, and educational maltreatment. Despite the growing empirical evidence on the prevalence and influence of different types of maltreatment, there are, however, clear gaps in the field. There is both empirical and conceptual evidence that the best understanding of characterizations of maltreatment and their differential outcomes is achieved by examining the subtypes separately and by taking the different levels of severity within each subtype into account $[2,3,4]$. There is a large body of evidence on the effects of child sexual abuse on child adjustment, but much less attention has been paid, for example, to physical abuse [5]. Also, the detailed analyses of the effects of different severity levels of maltreatment on children are practically missing [4].

The Developmental Victimization Survey of 2,030 American children [6] revealed that in the year preceding the survey, child maltreatment (broadly defined) occurred approximately in 1 in 7 of the 2-17 year old children and adolescents. Of the five maltreatment types measured in the study, emotional abuse was the most frequent, with $10 \%$ of children experiencing name calling or denigration by an adult. The large scale Finnish study of $7,3499^{\text {th }}$ graders conducted in 1988 showed that during the previous 12 months $47 \%$ of children experienced verbal aggression, 19\% were targets of mild physical violence such as slapping or pushing, and 5\% reported an experience of severe physical violence [7].

Maltreatment is thus a common phenomenon and therefore requires more detailed research. The meaning of different types of maltreatment should be investigated separately, and gender-based differences in reactions to maltreatment studied, in order to provide a better understanding of maltreatment. Also, comparative analyses between countries of the prevalence and meaning of maltreatment is needed to benchmark and identify urgent and important national specific problems or health goals. However, only few such studies have yet been published [8]. The Nordic countries have shown to have many similarities in youth victimization studies [9] but especially related to parental maltreatment, countries also have remarkable differences. Although across the Nordic countries, violence and maltreatment have been rather strictly defined and legislated against, there is a major difference between the two countries included in this study regarding the time when corporal punishment was made a penal act. In the Finnish 
criminal code, corporal punishment has been a penal act since 1984, whereas in Denmark the same law was not introduced until 1997. This creates an interesting setting for a comparative analysis.

In our study the focus is on the associations between parental violence with its three levels of severity and adolescents' mental health. In addition, comparative analyses of those results will be provided between genders and between the two Nordic countries, Denmark and Finland.

\section{Child physical abuse: Influence on child's mental health and social relations}

Previous studies have revealed that children who have been victims of abuse and neglect have more psychosocial problems, and they function less adaptively in several areas of development than do their non abused peers $[10,11,12] .$. Concerning physical abuse, some evidence exists that both internalizing and externalizing symptoms seem to occur among children and adolescents exposed to physical maltreatment, and that those who experience more serious physical abuse show more internalizing and externalizing behavioural problems than those who experience less serious abuse [13].

Fantuzzo [14] found that physically abused children showed significantly higher levels of aggression than their non-abused peers, even after controlling for several family related factors. Also, clinically significant externalizing symptoms have been reported to be significantly higher among physically abused children compared to the reference group. Ackerman et al. [15] found that children with a history of physical abuse have higher rates of oppositional defiant disorder and conduct disorder diagnoses compared to other maltreatment subcategories such as emotional neglect or sexual abuse. Additionally, in their longitudinal birth cohort study, Fergusson \& Lynskey [16] found that young people at age 18 reporting exposure to harsh or abusive treatment during childhood had elevated rates of violent offences, suicide attempts and alcohol abuse. Noteworthy, a meta-analysis of corporal punishment revealed similar results. Within 88 reviewed studies, corporal punishment was associated with several negative outcomes in childhood as well as in adulthood, including increased aggression, antisocial behaviour and abusive behaviour towards others [17].

There is also evidence of elevated levels of internalizing symptoms such as depression among physically abused children compared to the reference group [18]. Finzi et al. [19] substantiated the specific role of parental violence as a source of internalizing problems, reporting that children who were exposed to parental violence had more depressive symptoms and suicidal behaviour compared not only to non maltreated children but also to 
neglected children. Physical maltreatment has also been found to be associated with problems in dating partners and making close friends [20].

Exposure to parental violence in adolescence

In most studies, the "lifetime" count of maltreatment experiences has been used as a measure of violent situations in home environments and its impact on children's well being and mental health [21]. This research tradition, however, fails to show the specific effects of maltreatment experiences at a certain developmental stage, and more systematic research on the association between concurrent exposure to violence and the range of internalizing, externalizing and transitional outcomes has been asked for [22, 23]. In our study, we wanted to clarify the specific effects of the acute experiences of parental violence at the age of 15-16. We rely on adolescents self reports, which are regarded as an important and reliable source of information in older children $(8,24,25)$.

The extent of violent experiences varies among abused children. Barnett et al. [1], for example, found that among 11-14 year old children the extent of abusive experiences varied from a single incident of maltreatment to 14 years of recurring incidents of maltreatment. Also, results on the age differences of exposure to child maltreatment are controversial, some studies showing a decline in maltreatment experiences with age and some indicating higher rates of maltreatment experiences in adolescence than at a younger age [26, 27]. In the USA the Developmental Victimization Survey [6] revealed that physical abuse was highest among the teenage group, boys and girls experiencing similar rates of violence.

In addition to the emphasis on the detrimental nature of physical maltreatment in early childhood [28], the adverse consequences of adolescence-only maltreatment as well as persistent maltreatment are now seen as an important aspect of child mental health and behaviour [29]. So far very few studies apply the experimental comparative developmental approach within maltreatment research, but Stewart, Livingston \& Dennison [30] noticed that children whose maltreatment extended into adolescence had higher rates of offences than those with childhood-only maltreatment.

It is noteworthy that the most accurate reports of violent experiences are achieved by using a rather short referent period [31] and a one-year referent has been shown to be relevant [32].

\section{Research questions}

This study first examines whether different levels of parental violence (during the last 12 months) are differently associated with self-reported mental health, indicated by SDQ total problem score, internalizing and externalizing 
symptoms as well as prosocial behaviour. We hypothesized a dose-response effect between parental violent behaviour and the adolescent's problems. This means that we expected adolescents exposed to parental violence to have higher levels of mental health problems and lower levels of prosocial behaviour compared to adolescents without experience of parental violence. Further, we hypothesized that adolescents exposed to more severe forms of parental violence had increased levels of these problems compared to adolescents with exposure to milder levels of violence. Second, we examined whether the association between different severity levels of parental violence and mental health was gender or country specific.

\section{Method}

\section{Participants and procedure of the study}

The analysis in this article is based on the Finnish Child Victim Survey (2008) and Danish Youth (2008) study. The surveys covered a wide variety of violence against children, from traditional street violence and violence between peers to sexual abuse, family violence and bullying. In Finland the data was collected among $12-13\left(6^{\text {th }}\right.$ graders $)$ and $15-16\left(9^{\text {th }}\right.$ graders $)$ year old pupils. In this study only the data for $9^{\text {th }}$ graders is analysed. In Denmark the data was collected among $9^{\text {th }}$ graders.

In Finland, the survey was conducted by the Police College of Finland and in Denmark by the National Institute of Public Health, University of Southern Denmark in 2008. In both countries the surveys were based on multimedia computer-based self-administered interviews, which the children answered during school hours. The Finnish children accessed the questionnaire via a website which included information about the project as well as about violence in general. The survey was administered by teachers in the schools who were all properly instructed by the research team. The Danish survey was conducted in the school classroom where trained interviewers introduced the survey method, and they remained in the classroom while the students completed the questionnaire.

The data is a representative sample of mainland Finland and its Finnish and Swedish speaking $9^{\text {th }}$ graders as well as a representative sample of Danish $9^{\text {th }}$ grade pupils in the mandatory school system. The final Finnish sample consisted of 2,856 girls and 2,906 boys and the final Danish data 1,999 girls and 1,944 boys.

The Finnish sampling was drawn with a stratified cluster sample design based on county, quality of municipality and size of the school. The original sample included 184 schools with children in $9^{\text {th }}$ grade. Of those 161 participated to the survey (88\%). Data consisted of 5807 responses. The exact response rate can't unfortunately 
be presented because the variable needed to calculate that (namely the school ID), was vanished during the data collection. However, the representative nature of the final data was checked comparing basic socioeconomic factors to other representative studies (see more 33). Of the total amount of responses 45 were excluded due to lack of consistency in the answers. In the Danish survey, a random sample of 342 schools was selected from lists of all public, non-public, and institutional schools in Denmark. The schools were sampled randomly within six strata corresponding to different classifications of "percent urban" in the Danish census.. Of those, 122 schools participated (35\%). No important differences were found between the strata distribution of the participating and nonparticipating schools. There were 5,013 $9^{\text {th }}$ graders in those schools and 4,093 of those participated in the survey. Also in the Danish data, due to lack of consistency in some of the data sets, some responses were excluded from the data.

\section{Measures}

Parental violence was measured by Finnish and Danish versions of the Conflict Tactics Scale created by Straus [35]. The scale consists of 14 items beginning with parental aggressive verbalization towards the child and moving to severe violent acts towards the child. Participants responded by indicating whether they had experienced such acts $(1=$ yes $)$ or not $(0=$ no $)$ during the previous 12 months. The four groups indicating different severity levels of parental violence were formed based on these answers. The "No violence" group included children who had no experiences of verbal aggression or mild or severe physical violence. The "Verbal aggression" group included children who had experienced verbal aggression but no mild or severe physical violence. Acts of verbal aggression included items such as "sulking or refusing to talk, insulting or taunting or swearing, throwing objects and threatening with violence". The "Mild physical violence" group included children who had experienced mild parental violence accompanied or not accompanied by verbal aggression. Acts of mild physical violence included "pushing or shoving or shaking, hair pulling, smacking and whipping". The "Severe physical violence" group included children who had experienced severe parental aggression accompanied or not accompanied by acts of mild physiological violence and/or verbal aggression. Acts of severe physical violence included "battering, hitting with wrist, hitting with object, kicking, threatening with knife or gun and using a knife or gun".

An adolescent was included in one of the three violence groups if she/he had experienced at least one of the acts in a category. That means that there is a variation within the three groups on the frequency of experiences 
ranging from a onetime experience of one of the included acts, to several experiences of multiple included items. If the information about the experience was missing in some of those individual acts, the case was categorized as no experience before forming the summed variables. That was done to minimize the amount of missing data in the summed variables.

$S D Q$ total difficulties, internalizing and externalizing symptoms and prosocial behaviour were measured by the Strengths and Difficulties Scale (SDQ) by Goodman [36] The scale consists of 25 items on psychological attributes describing internalizing problems of depression and anxiety, and externalizing problems such as aggression and hyperactivity, plus prosocial behaviour. Participants evaluated how well the description fitted them on a 3 -point scale $(0=$ not true, $1=$ somewhat true, $2=$ certainly true $)$. Factor analysis (Varimax $)$ was applied to check the validity of dimensionality. The results revealed a somewhat different factor structure than the traditional five scale solution in SDQ and the reliability of the original dimensions of SDQ was low in the data (range $\alpha=.43-.68$ ). The best fitting factor solution in these analyses was a 3 -factor model. Based on these factors the averaged sum variables of externalizing, internalizing and pro-social behaviour were formed. The externalizing factor included 7 items ("I get very angry and often lose my temper", "I take things that are not mine from home, school or elsewhere", etc.), the internalizing factor included 8 items ("I have many fears, I am easily scared, I am often unhappy, down-hearted or tearful", etc.) and the prosocial factor 9 items ("I try to be nice to other people. I care about their feelings", "I am helpful if someone is hurt, upset or feeling ill”, etc.). The 20 items including questions about emotional symptoms (5items), conduct problems (5items), hyperactivity (5items) and peer relationship problems (5items) were added together to generate a SDQ total difficulties score. The test-retest reliabilities, internal consistency and criterion validity of these scales have been well established [36, 37]. The reliability of the SDQ for children's self reports was $\alpha=.67$ for SDQ total score, $\alpha=.71$ for internalizing symptoms, $\alpha=.71$ for externalizing symptoms and $\alpha=.65$ for pro-social behaviour.

\section{Statistical analysis}

To examine the associations between parental violence and child mental health, and their gender and nationality specificity the 4 (violence: no violence, verbal, mild and severe) X 2 (gender) X 2 (nationality) between subjects factorial multivariate analysis of variance (MANOVA) with their two-way interactions were applied to the dependent variables of the SDQ total difficulties score, internalizing symptoms, externalizing symptoms and 
prosocial behaviour. A Bonferroni correction was used to obtain a more conservative alpha level. The post hoc tests using the Tukey HSD post hoc criterion for significance were conducted to examine the differences between the four severity levels of parental violence. Examinations of the homogeneity of variance-covariance matrices and normality assumptions underlying MANOVA did not reveal any substantial anomalies.

\section{Results}

\section{Descriptive results}

In the Finnish sample $49 \%$ of girls and $74 \%$ of boys had no experiences of parental verbal aggression or physical violence during the previous 12 months. Differences between the sexes were clear in all severity levels of parental violence, with girls reporting higher exposure. Being the target of parental verbal aggression (girls 39\%, boys $20 \%$ ), mild physical violence (girls $10 \%$, boys $4 \%$ ) or severe physical violence (girls $2 \%$, boys $1 \%$ ) was two times more common among girls compared to boys.

In the Danish sample $58 \%$ of girls and $68 \%$ of boys reported no experiences of parental verbal aggression or physical violence during the previous 12 months. Being the target of parental verbal aggression (girls $43 \%$, boys $33 \%$ ) and mild physical violence (girls $9 \%$, boys $4 \%$ ) was more common among girls compared with boys, whereas the same number of girls and boys reported exposure to severe physical violence (girls $2 \%$, boys $2 \%$ ).

\section{Insert Table 1 about here}

\section{Parental violence and mental health}

Table 2 presents the main and interaction effects between exposure to parental violence, gender, country and mental health outcomes.

Main effect and Post hoc comparisons of parental violence. The results show a significant association between exposure to parental violence and SDQ total score $(\mathrm{F}(3,9185)=132.84 \mathrm{p}<.001)$, internalizing symptoms $(\mathrm{F}(3,9185)=75.90, \mathrm{p}<.001)$, externalizing symptoms $(\mathrm{F}(3,9185)=126.57, \mathrm{p}<.001)$, and prosocial behaviour $(\mathrm{F}(3,9185)=10.34, \mathrm{p}<.001)$ indicating that children experiencing the more severe forms of parental violence reported poorer mental health and prosocial behaviour.

The Post hoc comparisons using the Tukey HSD test indicated a clear dose-response effect. Concerning all symptom measures, the mean scores for exposure to parental verbal aggression ( $\mathrm{SDQ}$ total: $\mathrm{M}=12.19, \mathrm{SD}=5.15$; 
externalizing: $\mathrm{M}=.46, \mathrm{SD}=.35$; internalizing: $\mathrm{M}=.57, \mathrm{SD}=.37$ ) were significantly higher than in the no violence condition (SDQ total: $\mathrm{M}=10.47, \mathrm{SD}=4.81$; externalizing: $\mathrm{M}=.38, \mathrm{SD}=.34$; internalizing: $\mathrm{M}=.44, \mathrm{SD}=.33$ ). Further, the mean scores for exposure to mild violence ( $\mathrm{SDQ}$ total: $\mathrm{M}=14.37, \mathrm{SD}=5.40$, Externalizing: $\mathrm{M}=.61$, $\mathrm{SD}=.39$, internalizing: $\mathrm{M}=.66, \mathrm{SD}=.42$ ) were significantly higher than for verbal aggression. The mean scores for exposure to severe violence ( $\mathrm{SDQ}$ total: $\mathrm{M}=15.60, \mathrm{SD}=5.67$, externalizing: $\mathrm{M}=.75, \mathrm{SD}=.43$, internalizing: $\mathrm{M}=.73, \mathrm{SD}=.40$ ) were significantly higher than for exposure to mild violence concerning the externalizing symptoms but not SDQ total difficulties score or internalizing symptoms. Concerning the prosocial behaviour, however, only the mean scores for exposure to mild parental violence $(\mathrm{M}=1.21, \mathrm{SD}=.29)$ was significantly lower than in the no violence condition ( $\mathrm{M}=1.27, \mathrm{SD}=.33$ ), and there were no other significant differences. Interactions between exposure to parental violence, gender, nationality and mental health outcomes.

The association between parental violence and internalizing symptoms was gender specific, as evidenced by the significant interaction effect $(\mathrm{F}(1,9185)=5.24<.001)$. This means that a high level of parental violence was associated with internalizing symptoms especially among girls. Also, the association between parental violence and mental health was country specific as evidenced by the significant interaction effects of internalizing $(\mathrm{F}(1,9185)=4.98, \mathrm{p}<.01)$ and externalizing $(\mathrm{F}(1,9185)=3.67, \mathrm{p}<.05)$ symptoms and total SDQ total difficulties score $(\mathrm{F}(1,9185)=7.07, \mathrm{p}<.01)$. These interactions indicate that the exposure to parental violence was associated with mental health symptoms especially among Danish adolescents. Generally taken, the symptom scores, however, remained at a lower level in every class of parental violence exposure compared to Finnish adolescents. In other words, there were clearer differences between the classes of exposure to parental violence in symptom scores among Danish than Finnish youths.

\section{Main effects of gender and country}

There was a significant main effect of gender on internalizing symptoms $(F(1,9185)=9.96, p<.01)$ and externalizing symptoms $(\mathrm{F}(1,9185)=7.05, \mathrm{p}<.01)$ indicating that boys have higher levels of symptoms than girls. There was also a significant main effect of country on internalizing symptoms $(F(1,9185)=14.37, p<.001)$ and SDQ total score $(\mathrm{F}(1,9185)=270.35, \mathrm{p}<.001)$ and prosocial behaviour $(\mathrm{F}(1,9185)=1029.87, \mathrm{p}<.001)$ indicating that Finnish adolescents have higher levels of internalizing symptoms and total SDQ Psychological distress and lower level of prosocial behaviour than Danish adolescents. It is noteworthy that the mean score of total SDQ Psychological distress exceeded the cut-off score for the borderline/abnormal range among Finnish (16.43) but not Danish (14.96) 
adolescents experiencing severe parental violence (the SDQ cut-off score is 16 and it identifies $20 \%$ of the population; http://www.sdqinfo.com).

Insert Tables 2 about here

\section{Discussion}

Our results showed that about $40 \%$ of adolescents in both samples in this study had experienced verbal aggression and/or physical violence from their parents during the previous 12 months prior to the research, revealing a startling reality of negative experiences in the family context. That is much more than the results of the Child Victimization survey [6] among American children and youth showed, but much less than in the 1988 study among Finnish adolescents [7]. The American Child Victimization survey, however, excluded episodes of conventional corporal punishment. Exposure to parental violence was greater among girls than boys in this analysis. This was contrary to the findings from American samples showing similar exposure to minor violent acts among girls and boys, but which showed a slightly greater risk of severe physical abuse among boys compared with girls [38].

In line with earlier research $[39,40]$, the adolescents who reported more severe forms of parental violence also reported more severe psychological problems. It is important to note that the exposure to verbal aggression was associated with higher levels of total difficulties, internalizing and externalizing compared with the no violence condition. Thus, the verbal threatening and subjugation of a child may pose a risk to the adolescent mental health. Furthermore, when verbal aggression changes to or is accompanied by physical violence, the level of the adolescent's problems is even higher. This implies that the acts that are traditionally seen as corporal punishment such as slapping or pulling ones hair are acts that are frightening enough to produce agitation. The significance may lie in realizing that a parent, who is supposed to be protective and calm is acting unpredictably. The dose-response effect was not so evident concerning prosocial behaviour, even though adolescents who were exposed to mild parental violence reported poorer prosocial behaviour compared to adolescents with any experiences of parental violence. This trend of prosocial behaviour being less affected by adverse experiences may be seen as a resource for rehabilitation and prevention of mental health problems among exposed adolescents. Intact human relationships and adolescent's ability to act in positive ways outside the family context are of great importance when dealing with mental or behavioural difficulties. 
Only the internalization symptoms showed a gender specificity, high levels of parental violence being associated with internalizing symptoms. Girls exposed to parental violence in our study were more likely to react with symptoms of anxiety and depression compared to boys. The national differences found in our study imply that parental violence more strongly increases mental health symptoms among Danish adolescents, although we have to be aware that in general the level of symptoms remained lower compared to Finnish children. Thus, there were clearer differences between the classes of exposure to parental violence in symptom scores among Danish than among Finnish adolescents. The gender specificity in the association between parental violence and internalizing symptoms should make us cautious about drawing general conclusions. However, the adolescent attitudes towards parental violence should be taken into account when explaining the results. The results may also support the widely held view that there are huge individual differences in the way that individuals (both children and adults) respond to stress and adversity (41).

Although there is no detailed knowledge of the effects of parental violence according to developmental stages, adolescence is generally seen as a vulnerable period of exposure to a harmful home environment [42]. The vulnerability among the affected adolescents in this study manifested itself in elevated levels of SDQ total difficulties and internalizing and externalizing symptoms as well as some deterioration of prosocial behaviour. The fact that both internalizing and externalizing symptoms were associated with the level of parental violence implies that adolescents experience a wide variety of distress when exposed to an adverse home environment. Unfortunately our data does not allow us to take account of the strength of maltreatment in these different subtypes, which would also need further research. One incidence compared to continuous maltreatment may have different kinds of outcomes.

\section{Legislation}

In 1988, when the earlier Child Victim Survey was made in Finland [7], corporal punishment had been illegal for only four years. By the time of the current study twenty-four years have passed since it was prohibited. Concerning parental violence, the most outstanding difference between these two points of time can be seen in the prevalence of mild physical violence (including the acts that have traditionally been regarded as a form of corporal punishment). The number of children in Finland experiencing slapping and pushing, for example, by their parents in 
2008 had dropped to one third of what it was in 1988. The same trend, although not as clear as in mild physical violence, can also be seen in verbal and severe physical violence.

Among Finnish children in the current study sample, corporal punishment has been forbidden by law during their whole lifetime, whereas in Denmark the children in this study sample have spent approximately four of their first years living in communities where slapping, or pulling a child's hair, for example, was still legal. Noticing this difference in the timing of legally abandoning parental corporal punishment, it is interesting to compare the frequencies of parental violent acts between the two countries. Although maltreatment analysed here has occurred during the past 12 months of the survey, when maltreatment was illegal in both countries, it has been shown at least in Finland that attitudes towards physical punishment do not change rapidly (43), and therefore the prevalence of maltreatment may vary because of the difference in timing. The results, however, showed that the number of children who had experienced mild or severe physical violence within the previous 12 months was almost exactly the same in Finland and Denmark. The actual impact of the legislation can't be specified but the result is very interesting and reveals that Nordic countries, at least Denmark and Finland, do not differ so remarkably in experiencing maltreatment at home, although actions to prevent it may differ. Although slapping, or pulling a child's hair, for example, have been forbidden by law, there is still a minority of parents in both societies who do so anyway, while most of the parents do not punish their children that way. Discipline practices are closely related to cultural beliefs and, despite the empirical evidence of their negative consequences, they seem difficult to change [44].

\section{Co-occurring forms of adverse experiences}

We have to be aware of the fact that children's experiences within the previous 12 months reflect different kinds of violent history in their homes. When a child is exposed to psychological and physical violence, he/she could at the same time be exposed to other forms of maltreatment, such as sexual abuse or physical/emotional neglect. There is evidence that physical and psychological violence (emotional maltreatment) as well as a lack of general supervision tend to co-occur [39]. Likewise, interparental violence (often referred to as domestic violence) and parental violence towards children are, at least to some extent, co-occuring phenomena $[45,46]$. For example, mothers who are targets or perpetrators of partner violence are more prone to use physical violence towards their children than mothers who do not have such experiences [47]. 
This kind of accumulation of victim experiences most definitely also plays a role when associations between maltreatment and adolescents' mental health are studied. Witnessing interparental violence, for example, is linked to adverse mental health outcomes among children [for meta-analysis see for example 48, 49]. Finkelhor and others (50) have even suggested that taking so called poly-victimization into account, the impact of individual victimizations on mental health may even disappear. Knowledge of the accumulation of children's violent experiences thus stresses the need for a more comprehensive picture [6] and should be noted as a consequential factor behind our results, but doesn't diminish the importance to study also the meaning of parental maltreatment. According to our other research, although experiences of poly-victimization is taken into account and diminishes the impact of some other kinds of individual victimization, it does not make the impact of parental maltreatment on adolescents' mental health disappear [51]. In addition, it has been argued, that child maltreatment (physical abuse or neglect) is the form of victimization that has the strongest independent association with depression and anger/aggression [52].

\section{Limitations of the study:}

The Danish sample suffered from a relatively large number of schools who for several reasons did not participate. Although no important differences were found between the strata distribution of the participating and nonparticipating schools, there may be differences in the available schools from the non-participating schools on characteristics relevant to the study.

Given the cross-sectional nature of the study we have to be aware of the bi-directional nature of our findings. We have shown that parental use of violence (involving swearing, slapping, or even hitting the child) is associated with a child's mental problems. This association can reflect the harmful effect that parents behaviour is causing distress for a child, but it can also be the case that a child's behavioural or emotional problems might result in the parents being violent towards the child. Gelles \& Cornell [53] have suggested that the lack of scientific attention given to parental violence towards adolescents may have reflected the attitude that, because of their own difficult behaviour, adolescents share some complicity when receiving such mistreatment. Based on knowledge of the accumulation of adversity in family contexts it is also difficult to conclude whether the mental health problems found in this study are primary outcomes of physical abuse or of other problems within the family. Further research is needed to illuminate up the complex transactions between different family related factors and their influence on parental 
violence. This work was started by Jaffee [54], who found a genetically mediated relation between children's antisocial behaviour and their exposure to (nonnormative) physical maltreatment.

Additionally, the limitations of the widely used SDQ as a measure should be taken into account. The reliability of the original dimensions of SDQ was low in the data. The earlier applications of this measure were made in Sweden [55] and other Nordic countries [56]. Based on Nordic research the SDQ has shown to be an acceptable screening instrument for large community samples but it needs further evaluation. Its psychometric quality in particular should be improved $[57,56,58,55]$.

\section{Conclusions}

Knowledge of the prevalence of parental violence and the assessment of its effects should have implications for child protection, general health care, prevention and intervention. The findings of this article point to the high prevalence of parental violence and adverse mental health among the affected Finnish and Danish adolescents. It is noteworthy that among Finish adolescents experiencing severe parental violence the cut-off score for the borderline/abnormal range of SDQ total difficulties score was exceeded. Consequently, the recommendations based on our study could be the following; whenever the knowledge about parental use of severe violence such as hitting or kicking of a child/adolescent is achieved by social worker, nurse, psychologists etc. some psychosocial interventions should be offered. About $40 \%$ of Finish and Danish adolescents experience verbal and physical violence at the hand of their parents. The knowledge about its harmful effects could be delivered already in child health clinics and later in parental meetings at the school. The threshold for taking these issues under discussion should be low among professionals working with children and adolescents.

Even though the laws have been set in motion to prevent the use of parental physical violence the challenges remain in several domains: 1) controlling people's compliance with these laws, 2) creating conformity in the consequences when these laws are broken, 3) raising the general awareness of the detrimental effects of physical but also of the verbal aggression and subjugation of a child, 4) preventing harmful disciplinary practices and finally, implementing effective mental health interventions for children who have developed symptoms due to these harmful experiences. 
References

1. Barnett D, Manly JT, Cicchetti D (1993) Defining Child Maltreatment: The Interface between Policy and Research. In: Cicchetti D, Toth SL (eds) Child abuse, child development, and social policy. Ablex, Norwood, NJ, pp 7-74

2. Higgins DJ, McCabe MP (2000) Multi-type maltreatment and the long-term adjustment of adults. Child Abuse Review, 9: 6-18

3. Kinard EM (2001) Characteristics of maltreatment experience and academic functioning among maltreated children. Violence \& Victims, 16: 323-337

4. Litrownik AJ, Lau A, English DJ, Briggs E, Newton RR, Romney S, et al (2005) Measuring the severity of child maltreatment. Child Abuse \& Neglect, 29: 553

5. Corby B. (2006) Child abuse. Towards a knowledge base. Berk

6. Finkelhorn D, Ormrod R, Turner H, Hamby SL (2005) The victimization of children and youth: A comprehensive, national survey. Child Maltreatment, 10:5-25

7. Sariola H, Uutela A (1992) The prevalence and context of family violence against children in Finland. Child Abuse \& Neglect, 16: 823-832

8. Gilbert R, Spatz Widom C, Browne K, Fergusson D, Webb E, Janson S (2009) Burden and consequences of child maltreatment in high-income countries. Lancet, 373: 68-81

9. Enzmann D, Marshall I, Killias M, Junger-Tas J, Steketee M, Gruszczynska B (2010) Self-reported youth delinquency in Europe and beyond: First results of the Second International Self-Report Delinquency Study in the context of police and victimization data. European Journal of Criminology, 7: 159-183

10. Boney-McCoy S, Finkelhor D (1995) Psychosocial sequelae of violent victimization in a national youth sample. Journal of Consulting and Clinical Psychology, 63: 726-736

11. Holmes T, Robins L (1988) The role of parental disciplinary practices in the development of depression and alcoholism. Psychiatry, 51: 24-36

12. Trickett PK, McBride-Chang C (1995) The developmental impact of different forms of child abuse and neglect. Developmental Review, 311-337 
13. Stockhammer TF, Salzinger S, Feldman RS, Mojica E, Primavera LH. (2001) Assessment of the effect of physical child abuse within an ecological framework: Measurement issues. Journal of Community Psychology, 29: 319-344

14. Fantuzzo JW (1990) Behavioral treatment of the victims of child abuse and neglect. Behavior Modification, 14: 316-339

15. Ackerman PT, Newton JEO, McPherson WB, Jones JG, Dykman RA (1998) Prevalence of post traumatic stress disorder and other psychiatric diagnoses in three groups of abused children (sexual, physical, and both). Child Abuse \& Neglect, 22: 759-774

16. Fergusson DM, Lynskey MT (1997) Physical punishment/maltreatment during childhood and adjustment in young adulthood. Child Abuse \& Neglect, 21: 617-630

17. Gershoff TE (2002) Corporal punishment by parents and associated child behaviors and experiences: A metaanalytic and theoretical review. Psychological Bulletin, 128: 539-580

18. Pelcovitz D, Kaplan SJ, Ruth R (2000) Psychiatric disorders in adolescents exposed to domestic violence and physical abuse. American Journal of Orthopsychiatry, 70: 360-370

19. Finzi RPD, Ram AMD, Shnit DPD, Har-Even DMA, Tyano SMD, Weizman AMD (2001) Depressive symptoms and suicidality in physically abused children. American Journal of Orthopsychiatry, 71: 98-107

20. Wolfe DA, Wekerle C, Reitzel-Jaffe D, Lefebvre L (1998) Factors associated with abusive relationships among maltreated and nonmaltreated youth. Development and Psychopathology, 10: 61-85

21. Hanson R, Smith D, Saunders B, Swenson C, Conrad L (1995) Measurement in child abuse research: A survey of researchers. APSAC Advisor, 8: 7-10

22. Barnett OW, Miller-Perrin L, \& Perrin RD (2005) Family violence across the lifespan. Thousand Oaks, California

23. Foster H, Brooks-Gunn J (2009) Toward a stress process model of children's exposure to physical family and community violence. Clinical Child \& Family Psychology Review, 12: 71-94

24. Fergusson DM, Horwood LJ, Woodward LJ (2000) The stability of child abuse reports: a longitudinal study of the reporting behaviour of young adults. Psychol Med, 30: 529-44.

25. Finkelhor D (2008) Childhood victimization. Violence, crime and abuse in the lives of young people. Oxford: Oxford University Press. 
26. Belsky J (1993) Etiology of child maltreatment: A developmental-ecological analysis. Psychological Bulletin, 114: 413

27. Cohen P, Brown J, Smailes E. (2001) Child abuse and neglect and the development of mental disorders in the general population. Development and Psychopathology, 13: 981-999

28. Keiley MK, Howe TR, Dodge KA, Bates JE, Pettit GS (2001) The timing of child physical maltreatment: A cross-domain growth analysis of impact on adolescent externalizing and internalizing problems. Development and Psychopathology, 13: 891-912

29. Thornberry TP, Ireland, TO, Smith CA (2001) The importance of timing: The varying impact of childhood and adolescent maltreatment on multiple problem outcomes. Development and Psychopathology, 13: 957-979

30. Stewart A, Livingston M, Dennison S (2008) Transitions and turning points: Examining the links between child maltreatment and juvenile offending. Child Abuse and Neglect, 32: 51-66

31. Czaja R, Blair J, Bickart B, Eastman E (1994) Respondent strategies for recall of crime victimization incidents. J. Off. Stat., 10: 257-276

32. Hamby SL, Finkelhorn D (2000) The victimization of children: Recommendations for assessment and instrument development. Journal of the American Academy of Child and Adolescent Psychiatry, 39: 829-840

33. Ellonen N, Käriäinen J, Salmi V, Sariola H (2008) Lasten ja nuorten väkivaltakokemukset [The experiences of violence among children and young people]. Tampere: Police College of Finland.

34 Helweg-Larsen K, Schütt NM, Larsen HB (2009) Unges trivsel År 2008. En undersogelse med fokus på seksuelle overgreb i barndommen. Statens Institut for Folkesundhed: Copenhagen.

35. Straus MA. (1979) Measuring intra family conflict and violence: The Conflict Tactics Scale. Journal of Marriage and the Family, 41: 75-88.

36. Goodman R (1997) The strengths and difficulties questionnaire: A research note. Journal of Child Psychology and Psychiatry, 38: 581-586

37. Bourdon KH., Goodman R, Rae DS, Simpson G, Koretz DS (2005) The strengths and difficulties questionnaire: U.S. Normative data and psychometric properties. Journal of the American Academy of Child \& Adolescent Psychiatry, 44: 557-564

38. Sedlak AJ, Broadhurst DD (1996) The third national incidence study of child abuse and neglect. Department of Health and Human Services, Administration for Children and Families, Washington, DC 
39. Bolger KE, Patterson C J, \& Kupersmidt JB (1998) Peer relationships and self-esteem among children who have been maltreated. Child Development, 69:1171 - 1197

40. Stockhammer TF, Salzinger S, Feldman RS, Mojica E, Primavera LH. (2001) Assessment of the effect of physical child abuse within an ecological framework: Measurement issues. Journal of Community Psychology, 29: 319-344

41. Rutter M (2009) Understanding and testing risk mechanisms for mental disorders. Journal of Child Psychology and Psychiatry 50: pp 44-52.

42. Demaris A, Kaukinen C (2005) Violent victimization and women's mental and physical health: Evidence from a national sample. Journal of Research in Crime \& Delinquency, 42: 384

43 Sariola H (2007) Älä lyö lasta kampanja muutti asenteita [Don’t hit the child - campaign changed attitudes towards physical punishment] Haaste, 4: 7-10

44. Westby AE (2007) Child maltreatment: A global issue. Language, Speech, \& Hearing Services in Schools, 38 : $140-148$

45. Edleson JL (1999) The overlap between child maltreatment and woman battering. Violence Against Women, $5: 134-154$

46. Holt S, Buckley H, Whelan S (2008) The impact of exposure to domestic violence on children and young people: A review of the literature. Child Abuse \& Neglect, 32: 797-810

47. Ross SM (1996) Risk of physical abuse to children of spouse abusing parents. Child Abuse \& Neglect, 20: 589598

48. Evans SE, Davies C, DiLillo D (2008) Exposure to domestic violence: A meta-analysis of child and adolescent outcomes. Aggression \& Violent Behavior, 13: 131

49. Kitzmann KM, Gaylord NK, Holt AR, Kenny ED (2003) Child witnesses to domestic violence: A meta-analytic review. Journal of Consulting and Clinical Psychology, 71: 339-352

50 Finkelhor D, Ormrod RK, Turner HA (2007). Poly-victimization: A Neglected Component in Child Victimization. Child Abuse \& Neglect, 31: 7-26

51. Ellonen N, Peltonen K, Salmi V Moninaisen väkivallan moninaiset vaikutukset lasten psykososiaaliseen hyvinvointiin [Multiple effects of multiple violence on child psychosocial wellbeing], manuscript 
52. Turner HA, Finkelhor D, Ormrod R (2006) The effect of lifetime victimization on the mental health of children and adolescents. Social Science \& Medicine, 62: 13

53. Gelles RJ, Cornell CP (1990) Intimate violence in families, vol. 2. CA: Sage, Beverly Hills

54. Jaffee SR., Caspi A, Moffitt TE, Polo-Tomas M, Price TS, Taylor A (2004) The limits of child effects: Evidence for genetically mediated child effects on corporal punishment but not on physical maltreatment. Developmental Psychology, 40: 1047

55. Svedin C, Priebe G (2008) The strengths and difficulties questionnaire as a screening instrument in a community sample of high school seniors in Sweden. Nordic Journal of Psychiatry, 63: 225-232

56. Obel C, Heiervang E, Rodriguez A, Heyerdahl S, Smedje H, Sourander A. et al (2004) The strengths and difficulties questionnaire in the Nordic countries. European Child \& Adolescent Psychiatry, 13: 32-39

57. Goodman R, Meltzer H, Bailey V (1998) The strengths and difficulties questionnaire: A pilot study on the validity of the self-report version. European Child \& Adolescent Psychiatry, 7: 125-130

58. Rønning J, Handegaard B, Sourander A, \& Mørch W-T (2004) The strengths and difficulties self-report questionnaire as a screening instrument in Norwegian community samples. European Child \& Adolescent Psychiatry, 13, 73-82

Tables

Table 1

Frequencies and percentages of exposure to parental violence according to nationality and gender 


\begin{tabular}{lllllllllllll}
\hline Parental Violence & $\mathrm{n}$ & $\%$ & $\mathrm{n}$ & $\%$ & $\mathrm{n}$ & $\%$ & $\mathrm{n}$ & $\%$ & $\mathrm{n}$ & $\%$ & $\mathrm{n}$ & $\%$ \\
\hline No violence & 3589 & 62 & 1404 & 49 & 2172 & 75 & 2447 & 61 & 1324 & 66 & 1092 & 56 \\
Verbal aggr. & 1679 & 29 & 1099 & 39 & 580 & 20 & 1270 & 32 & 581 & 29 & 682 & 35 \\
Mild phys. viol. & 408 & 7 & 295 & 10 & 113 & 4 & 195 & 5 & 56 & 3 & 139 & 7 \\
Severe phys. viol. & 99 & 2 & 58 & 2 & 41 & 1 & 74 & 2 & 38 & 2 & 31 & 2 \\
Total & 5775 & 100 & 2856 & 100 & 2906 & 100 & 3986 & 100 & 1999 & 100 & 1944 & 100 \\
\hline
\end{tabular}

Table 2

\begin{tabular}{|c|c|c|c|c|c|c|c|c|}
\hline & \multicolumn{2}{|c|}{ SDQ total difficulties } & \multicolumn{2}{|c|}{ Externalizing } & \multicolumn{2}{|c|}{ Internalizing } & \multicolumn{2}{|c|}{ Pro-social } \\
\hline & $\mathrm{M}$ & $\mathrm{SD}$ & $\mathrm{M}$ & SD & $\mathrm{M}$ & $\mathrm{SD}$ & $\mathrm{M}$ & $\mathrm{SD}$ \\
\hline \multicolumn{9}{|c|}{ Parental violence } \\
\hline No violence & 10.47 & 4.81 & .38 & .34 & .44 & .33 & 1.27 & 33 \\
\hline
\end{tabular}




\begin{tabular}{|c|c|c|c|c|c|c|c|c|}
\hline Verbal aggression & 12.19 & 5.15 & .46 & .35 & .57 & .37 & 1.29 & .32 \\
\hline Mild phys. violence & 14.37 & 5.40 & .60 & .39 & .66 & .42 & 1.22 & .29 \\
\hline Severe phys. viol. & 15.60 & 5.67 & .74 & .43 & .73 & .40 & 1.26 & .39 \\
\hline F-value & $143.99 * * *$ & & $126.57 * * *$ & & $75.90^{* * *}$ & & $10.34 * * *$ & \\
\hline \multicolumn{9}{|l|}{ Gender } \\
\hline Girl & 10.96 & 4.83 & .40 & .35 & .48 & .35 & 1.26 & 35 \\
\hline Boy & 11.70 & 5.40 & .45 & .37 & .53 & .37 & 1.28 & .29 \\
\hline F-value & .16 & & $7.05^{*}$ & & $9.96 * *$ & & 1.22 & \\
\hline \multicolumn{9}{|l|}{ Country } \\
\hline Finland & 12.57 & 4.71 & .43 & .36 & .53 & .37 & 1.11 & .24 \\
\hline Denmark & 9.59 & 5.19 & .41 & .36 & .47 & .35 & 1.50 & .30 \\
\hline F-value & $138.80 * * *$ & & .06 & & $14.37 * *$ & & $1029.87 * * *$ & \\
\hline \multicolumn{9}{|l|}{ Parental viol*Gender } \\
\hline F-value & 1.75 & & .37 & & $5.24 * *$ & & 1.29 & \\
\hline \multicolumn{9}{|l|}{ Parental viol*Cuuntry } \\
\hline F-value & $367.33^{* *}$ & & $3.66^{*}$ & & $4.98 * *$ & & .07 & \\
\hline
\end{tabular}

Main and interaction effects of parental violence, gender and country on mental health outcomes

$* \mathrm{p}<.05 * * \mathrm{p}<.01 * * * \mathrm{p}<.001$ (the significance levels with Bonferroni correction 
